\title{
Preparation for Cardiopulmonary Resuscitation in Medical Schools in Australia: A Survey of Current Practice
}

\author{
Peter J. M. Barton, Andrew A. Beveridge, and Kay M. Jones \\ Department of General Practice, Monash University, Building 1, 270 Ferntree Gully Road, Notting Hill, VIC 3168, Australia \\ Correspondence should be addressed to Peter J. M. Barton; peter.barton@monash.edu
}

Received 31 January 2013; Accepted 27 February 2013

Academic Editors: H. J. Baumann, F. Bilotta, and A. M. Japiassu

Copyright ( 2013 Peter J. M. Barton et al. This is an open access article distributed under the Creative Commons Attribution License, which permits unrestricted use, distribution, and reproduction in any medium, provided the original work is properly cited.

\begin{abstract}
Introduction. Cardiopulmonary resuscitation (CPR) is acknowledged worldwide as a stressful clinical activity for all young doctors. The extent of standardisation of preparation for CPR within Australian curricula is unknown. Recent trends in the UK suggest the emergence of a common endpoint, Immediate Life Support (ILS) certification. The support for a similar shared endpoint in Australia is unknown. Methodology. A telephone questionnaire survey about the preparation for teaching CPR to medical students was undertaken in all Australian medical schools in early 2012; 88\% of schools replied. Results. The majority favoured early basic CPR training. There was marked variation in how schools taught advanced CPR and how CPR competence was assessed. Only one school considered their graduates to be less than well prepared for CPR and all schools agreed that a common endpoint was desirable. Discussion. There is broad support for Immediate Life Support as a common end in resuscitation competence. Medical schools where students are prepared for a rural placement on graduation may still require a higher standard of competence.
\end{abstract}

\section{Introduction}

Competent cardiopulmonary resuscitation (CPR) is a necessary skill for medical graduates. The few studies conducted in Australia that discusses junior doctors' preparedness and education experiences report that the junior doctors demonstrate a broad range of competence levels. Using selfrating scales, some junior doctors report feeling well prepared for resuscitation and managing emergencies whilst others feel their preparation is inadequate [1-4]. Similar variation has also been reported for chiropractic and undergraduate nursing students in Australia [5]. Comparable literature from overseas is limited, but similar experiences are reported for medical students from the United Kingdom [6-9] and Germany [10]. Common themes from these studies include significant anxiety and a lack of confidence in undertaking CPR.

Whilst CPR is usually embedded within a broader curriculum in emergency medicine [11], there remains variation in curricular processes, delivery mechanisms, assessment philosophies, and required outcomes at the national level. Benchmarking and disseminating current practice of CPR preparation (teaching and assessment) are part of normal curricula renewal. The first international consensus curriculum in undergraduate emergency medicine, involving contributions from more than fifty countries, was only developed as recently as 2009 [11].

In Australia, emergency medicine teaching has relied on local initiatives; for example, basic and advanced life support, triage, and prehospital care were introduced at the University of Western Australia in 1997. This initiative also attempted to standardise the teaching materials developed for similar teaching over that university's four campuses [1]. The first International Liaison Committee on Resuscitation (ILCOR) was hosted by the American Heart Association in 1999 and led to the publication of international guidelines in 2000 for cardiopulmonary resuscitation and emergency cardiovascular care [4]. Since then, there has been significant development with the Australian Curriculum Framework for Junior Doctors being launched in 2006 [3, 12], but CPR competence was not defined. The same year, the Australian Resuscitation Council acquired the cobadging rights to the Immediate Life Support (ILS) and Advanced Life Support (ALS) courses from The Resuscitation Council of the United 
Kingdom. The UK ILS Resuscitation Council course is accepted as the baseline resuscitation standard for clinicians in Europe. Australia frequently benchmarks standards of care against European or North American health care systems. In 2010 the Australian Resuscitation Council and the New Zealand Resuscitation Council (ARC\&NZRC) partnered for the first time to copublish joint resuscitation guidelines [4].

With these significant changes in the last decade, the aims of this research were to identify

(1) the educational strategy and value attached to resuscitation in undergraduate medical curricula in universities in Australia, including the mix of formative and summative assessments used in demonstrating clinical competence,

(2) the clinical discipline of those responsible for delivery and assessment of these curricula, including ongoing development of curricula,

(3) the extent of institutional interest in a common resuscitation competence in resuscitation, in particular, institutional support for ILS certification.

The outcomes from this work will be of importance and interest to curriculum developers in medical schools in Australia, national and state regulatory bodies for clinical standards, the Australian Resuscitation Council, and the wider public, particularly those in rural or remote environments and medical graduates transitioning into practitioners.

\section{Method}

A questionnaire was developed, informed by a review of the literature and slight amendments to the questionnaire used in three previous surveys of UK medical schools, due to the inclusion of the internationally accredited ILS [9]. The questionnaire uses a mixture of specific responses and free text comments.

All eighteen medical schools in Australia were contacted by telephone to ascertain the person responsible for CPR curriculum in the medical school curriculum, and then that person was invited to participate in the research. Attempts to contact the relevant person were terminated after six failed attempts. A letter of invitation, explanatory statement, informed consent form, and revocation of consent was forwarded to those contacted. Receipt of the signed form indicated the individual's agreement to participate. An offer to conduct the survey by telephone by one of the researchers (PJMB) was accepted by ten participants. Six participants completed the questionnaire and returned these directly to the researchers.

Ethics approval was granted by Monash University Human Research Ethics Committee (MUHREC).

\section{Results}

The survey was undertaken between December 2011 and February 2012. Of the 18 medical schools, 17 were successfully contacted and agreed to provide deidentified data. Of the
17 , one did not return data; final responses were therefore received from 16 of the 18 universities (response rate $88 \%$ ).

While some medical schools offer students several programs, for example both medical schools in Melbourne offer curricula of different duration due to different entry requirements (from secondary school or previous degree), respondents were asked to reply on behalf of their overall MBBS curricular policy.

Eight medical schools offered a graduate entry program (4 years), and eight offered an undergraduate program (5-6 years), of which, one was a transitioning to a graduate program. Australian university medical schools' curricula differ from the UK where almost all medical schools are 5-year undergraduate courses. To accommodate these differences, the team changed the reporting categories from the strict years of attendance to three categories; "start of the program", "middle of program", and "end of program".

During three telephone interviews, clarification was offered as to what was meant by Basic Life Support (BLS), Immediate Life Support (ILS) [9], and Advanced Life Support (ALS). The three universities were in three different states and indicated they offered an equivalent course to ILS; an "equivalent to ALS" category was introduced to accommodate this.

All medical schools offered Basic CPR, and twelve (75\%) did so during year 1 . Three included an external certification of basic life support competence from a recognised first aid organisation as a precondition of entry. Three offered curricula with a preclinical and clinical split and Basic CPR training midway through the academic program. This contrasted with thirteen universities whose curricula of clinical expertise were integrated from the first year. One university's curriculum offered basic CPR in the final year of the academic course.

Once taught, thirteen (81\%) medical schools assessed maintenance of CPR skills annually, one assessed biennially, and two did not assess maintenance of CPR skills. The assessment of skills varied considerably.

Ten medical schools timetabled the teaching of advanced skills, for example, use of defibrillator, around the midpoint of curricula, one offered instruction very early in their curriculum, and five did so at the end of the academic course. The eleven universities where CPR was taught before the end of a curriculum were reassessed annually; five used a single end of curriculum assessment. Eight conducted summative assessments only and eight used formative and summative assessments (Table 1).

Two medical schools required ILS certification for graduation purposes. Four reported offering an equivalent course and one offered ALS. The respondent considered that this course was equivalent to Australian Resuscitation Council course; however, the course was not certified by the Australian Resuscitation Council. Nine medical schools (62\%) did not offer a formal ILS course (Table 2).

Fourteen medical schools ( $87 \%)$ reported that they considered their graduates to be effective in delivering CPR. One considered that the current student educational teaching offered was inadequate; the other consulted their end of year Objective Structured Clinical Examination (OSCE) results 
TABLE 1: Teaching and assessment.

\begin{tabular}{|c|c|c|}
\hline $\mathrm{CPR}$ taught/assessed & $\begin{array}{l}\text { When and } \\
\text { assessment format }\end{array}$ & \\
\hline \multirow{4}{*}{ Basic CPR teaching } & Yes & $16 / 16(100 \%)$ \\
\hline & Start of program & $12 / 16(75 \%)$ \\
\hline & Middle of program & $3 / 16(19 \%)$ \\
\hline & End of program 4 & $1 / 16(6 \%)$ \\
\hline \multirow{6}{*}{ Basic CPR assessment } & Assessed annually & $13 / 16(62 \%)$ \\
\hline & Assessed biennially & $1 / 16(6 \%)$ \\
\hline & Did not assess & $2 / 16(12.5 \%)$ \\
\hline & Formative only & Nil \\
\hline & $\begin{array}{l}\text { Summative only, } \\
\text { including externals }\end{array}$ & $4 / 16(25 \%)$ \\
\hline & $\begin{array}{l}\text { Mixed formative } \\
\text { and summative }\end{array}$ & $10 / 16(63 \%)$ \\
\hline \multirow{3}{*}{$\begin{array}{l}\text { Advanced skills (manual and } \\
\text { automated defibrillator use, } 2 \\
\text { person CPR) teaching }\end{array}$} & Start of program & $1 / 16(6 \%)$ \\
\hline & Middle of program & $10 / 16(62 \%)$ \\
\hline & End of program & $5 / 16(32 \%)$ \\
\hline \multirow{5}{*}{$\begin{array}{l}\text { Advanced skills (manual and } \\
\text { automated defibrillator use, } 2 \\
\text { person CPR) assessment }\end{array}$} & Annually & $11 / 16(69 \%)$ \\
\hline & Not reassessed & $5 / 16(31 \%)$ \\
\hline & Formative only & Nil \\
\hline & Summative only & $8 / 16(50 \%)$ \\
\hline & $\begin{array}{l}\text { Mixed formative } \\
\text { and summative }\end{array}$ & $8 / 24(50 \%)$ \\
\hline
\end{tabular}

TABLE 2: ILS certification offered.

\begin{tabular}{llc}
\hline ILS & Offered & \\
\hline & ILS offered & $2 / 16(12 \%)$ \\
Immediate Life Support & Equivalent to ILS offered & $4 / 16(25 \%)$ \\
certification & ALS offered & $1 / 16(6 \%)$ \\
& No ILS offered & $9 / 16(63 \%)$ \\
\hline
\end{tabular}

and then stated that these disappointingly demonstrated their students' lack of competence (Table 3).

Staff from various backgrounds and clinical responsibilities was employed to train students (Table 3). Three (19\%) used external first aid organisations, for example St John's Ambulance, but as skills required and interventions became more advanced, medical schools used staff from a variety of disciplines; five (31\%) used paramedics recruited from local health services or from university departments; five (31\%) used specialised medical educators from within the medical school, and four (25\%) used a mixture of emergency and clinical staff to teach certain aspects of advanced CPR. These clinicians were a mixture of both medical and specialised nursing staff from intensive care units or anaesthetists (Table 3).

All respondents considered a common Australian graduate competence to be desirable. The level of competency favoured varied; nine $(56 \%)$ preferred ILS, four $(25 \%)$ preferred an Australian ILS/ALS hybrid, and three (19\%) ALS (Table 3).

\section{Discussion}

There was close-to-universal agreement about introducing CPR early in medical studies. Of the 16, one did not support teaching CPR early in an undergraduate curriculum although one offered a course midway through the curriculum. However, there was less agreement about when the optimal time in the curriculum would be for advanced skills to be taught. While there was consensus that skills need to be reassessed at least annually, there was significant variation in the assessment methods used; half $(n=8 / 16)$ used summative only and half $(n=8 / 16)$ used both formative and summative methods.

The confidence expressed by participants in the effectiveness of the courses offered and graduates' capacity to perform CPR is equivalent to that reported by research conducted in the UK [6], although the outcomes are achieved through varying methods. In Australia, the majority of universities have unique, often long standing teaching programs that involve simulated learning environments and intensive care units, usually calling on personal relationships to deliver teaching. Many respondents were genuinely proud of their curricular commitment to CPR preparation and discussed its place within their emergency medicine teaching programs. Whilst supportive of a common national standard, many stressed that the critical care educational programs currently offered provide excellent clinical preparation. Several felt the involvement of volunteer staff from intensive care units offered a significant advantage for subsequent integration of graduates into these emergency settings once students are qualified.

Medical curricula continue to be refined by published international standards of clinical care. As curricular consensus is forged within the emergency medicine community, targeted teaching resources should be defined and supplementary assessment opportunities identified to meet international criteria. Staff from a wide variety of backgrounds delivers CPR training and often such teaching relies on personal relationships. Formal service level arrangements could be more regularly contemplated to both reward and recognise this commitment and ensure continued availability of teaching resources as clinician's time is squeezed. Adequate staffing is essential, especially when competition for teaching resource occurs between undergraduate and postgraduate faculties and between different health professionals. Unlike the UK, in Australia, as yet, there is no provision for "resuscitation training officers", whose cross disciplinary clinical remit is the training of all staff for basic, intermediate, and advanced resuscitation (Box 1).

UK resuscitation training officers invariably come from an emergency care clinical background; most often they are registered emergency nurses or paramedics and they must be qualified to teach both ILS and ALS as per the UK Resuscitation Council requirements.

The adoption of ILS as the standard for basic hospital based resuscitation training offers an ideal starting point from which it could extend to a common standard in resuscitation across medical curricula delivered in universities in Australia. The recent rebadging by the Australian Resuscitation Council 
TABLE 3: Training effectiveness, training provision, and competencies.

\begin{tabular}{|c|c|c|}
\hline Provision and competence & Provider and competence level & \\
\hline \multirow{3}{*}{$\begin{array}{l}\text { Have your graduates received adequate training } \\
\text { to be effective in performing CPR }\end{array}$} & Yes & $14 / 16(88 \%)$ \\
\hline & No & $2 / 16(12 \%)$ \\
\hline & No answer & Nil \\
\hline \multirow{4}{*}{ Who provides training of students? } & External agencies (for example, St John's ambulance at the beginning) & $3 / 16(19 \%)$ \\
\hline & Paramedics & $5 / 16(31 \%)$ \\
\hline & $\begin{array}{l}\text { Clinical staff: intensive unit (nursing and medical) and anaesthetic } \\
\text { specialists }\end{array}$ & $16 / 16(100 \%)$ \\
\hline & Specialised trained nurses (dedicated medical educators) & $4 / 16(25 \%)$ \\
\hline \multirow{2}{*}{ Would you favour a common competence? } & Yes & $16 / 16(100 \%)$ \\
\hline & No & Nil \\
\hline \multirow{3}{*}{ What should this competence be? } & Immediate Life Support (ILS) & $9 / 16(56 \%)$ \\
\hline & Advanced Life Support (ALS) & $3 / 16(19 \%)$ \\
\hline & Australian hybrid of ILS and ALS & $4 / 16(25 \%)$ \\
\hline
\end{tabular}

This is an opportunity for a motivated individual to assist in the promotion and facilitation of the Resuscitation Training Service across the Trust.

The successful applicant will work within a team, under the direction and guidance of the Principal Resuscitation Officer. You will have a keen interest in education and resuscitation training, and possess the confidence and enthusiasm to enhance resuscitation skills by effective delivery of education and training programmes to appropriate hospital and community based staff, and other external agencies.

You will be required to assist in the provision of all aspects of the Resuscitation Service deputising when required.

The Royal Bournemouth \& Christchurch Hospitals NHS Trust covers 2 sites. The Resuscitation Training Department is based at the Royal Bournemouth Hospital and also benefits from a Simulation Suite.

In addition to an internal training programme, the Trust is currently a Resuscitation Council (UK) accredited centre for PILS, ILS and ALS courses.

Applicants should be a Registered Nurse, ODP or Paramedic with a minimum of 3 years post qualification experience in the critical/emergency care setting with experience working in the hospital environment.

Job share would be considered.

Applicants are required to have:

Current Resuscitation Council (UK) Advanced Life Support instructor/candidate/or recommended instructor.

Sound post registration experience.

A recognised teaching qualification that is, ENB 998, C \& G 730 Part 1 \& 2.

A Current Resuscitation Council (UK) EPLS/APLS Instructor/candidate/recommended instructor/or provider Certificate.

Excellent communication, interpersonal and organisational skills

The ability to be self-motivated and flexible.

Able to work in a team environment.

Ability to work on own initiative, unsupervised and alone.

Standard keyboard and good computer skills

A driving license and access to a car.

Box 1: Advertisement from NHS website for a resuscitation training officer.

of the ILS course would be a positive option offering alignment with a European standardised curriculum for interns. Consideration could be given to contextualisation of these courses to reflect both the severity and nature of rural injuries and the likely levels and time frames for access to support for interns, as doctors in rural hospital locations are often the first responders in the hospital and must manage until senior staff arrives. Anecdotal evidence (PB doctorial study in preparation) suggests that medical schools that serve rural populations should therefore continue to prepare their graduates for more isolated and independent practice than is encountered in metropolitan practice. 
The ALS course is generally three days in duration and is of most benefit to those with significant experience of ongoing critical care, such as those whose responsibility extends significantly beyond the immediate resuscitation event itself. In the UK attending courses is restricted to post-graduatelevel clinicians by the UK Resuscitation Council.

\section{Conclusions}

Medical schools in Australia are staffed by dedicated clinicians and educators who are committed to preparing graduates to provide high-quality emergency care including CPR. Promoting standardisation of CPR courses, through the requirement for ILS certification, offers a single internationally benchmarked measure. The introduction of compulsory ILS certification may also ensure consistent care to patients and may improve levels of confidence for graduating doctors in their first CPR experience as a professional.

Limitations of this study (like its UK predecessors) include those of any study where one individual represents the activity of an entire curriculum. This may be overcome if the individual responsible in a particular school can be identified and a detailed telephone interview undertaken.

Generalisability; it would be useful for other developed countries to review their overall preparation for newly qualified doctors to undertake CPR and to determine whether consensual national and perhaps international standards can be promoted and established.

Further studies will establish whether offering a more standardised approach to CPR preparation and training will reduce novice clinicians' anxiety when undertaking this critical task.

\section{Authors' Contribution}

All authors contributed to the paper.

\section{References}

[1] A. Celenza, G. A. Jelinek, I. Jacobs, C. Kruk, R. Graydon, and L. Murray, "Implementation and evaluation of an undergraduate emergency medicine curriculum," Emergency Medicine, vol. 13, no. 1, pp. 98-103, 2001.

[2] G. Duns, T. Weiland, B. Crotty, B. Jolly, H. Cuddihy, and A. Dent, "Self-rated preparedness of Australian prevocational hospital doctors for emergencies," Emergency Medicine Australasia, vol. 20, no. 2, pp. 144-148, 2008.

[3] J. J. Gome, D. Paltridge, and W. J. Inder, "Review of intern preparedness and education experiences in General Medicine," Internal Medicine Journal, vol. 38, no. 4, pp. 249-253, 2008.

[4] P. Leman and I. Jacobs, "What is new in the Australasian Adult Resuscitation Guidelines for 2010?” Emergency Medicine Australasia, vol. 23, no. 3, pp. 237-239, 2011.

[5] P. Josipovic, M. Webb, and I. McGrath, "Basic life support knowledge of undergraduate nursing and chiropractic students," Australian Journal of Advanced Nursing, vol. 26, no. 4, pp. 58-63, 2009.
[6] P. J. M. Barton and J. McGowan, "A survey of undergraduate resuscitation training in UK medical schools," Resuscitation, vol. 815, pp. S1-S114, 2010.

[7] R. Morgan and C. Westmoreland, "Survey of junior hospital doctors' attitudes to cardiopulmonary resuscitation," Postgraduate Medical Journal, vol. 78, no. 921, pp. 413-415, 2002.

[8] G. Scott, E. Mulgrew, and T. Smith, "Cardiopulmonary resuscitation: attitudes and perceptions of junior doctors," Hospital Medicine, vol. 64, no. 7, pp. 425-428, 2003.

[9] C. A. Graham, K. A. Guest, and D. Scollon, "Cardiopulmonary resuscitation. Paper 1: a survey of undergraduate training in UK medical schools," Journal of Accident and Emergency Medicine, vol. 11, no. 3, pp. 162-164, 1994.

[10] S. K. Beckers, A. Timmermann, M. P. Müller, M. Angstwurm, and F. Walcher, "Undergraduate medical education in emergency medical care: a nationwide survey at German medical schools," BMC Emergency Medicine, vol. 9, article 7, 2009.

[11] C. Hobgood, V. Anantharaman, G. Bandiera et al., "International federation for emergency medicine model curriculum for medical student education in emergency medicine: position paper," Emergency Medicine Australasia, vol. 21, no. 5, pp. 367$372,2009$.

[12] I. S. Graham, A. J. Gleason, G. W. Keogh et al., "Australian curriculum framework for junior doctors," The Medical Journal of Australia, vol. 186, no. 7, pp. S14-S19, 2007. 


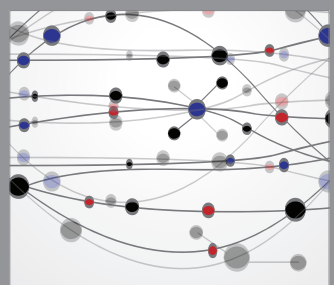

The Scientific World Journal
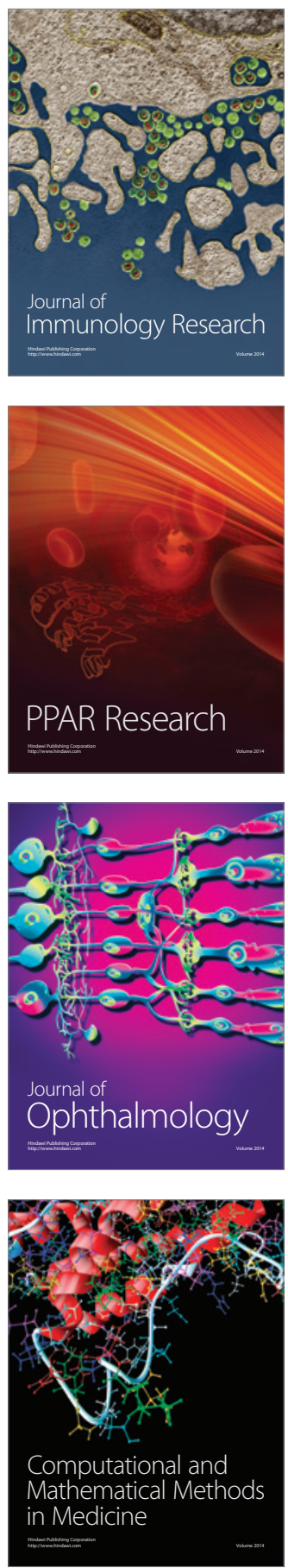

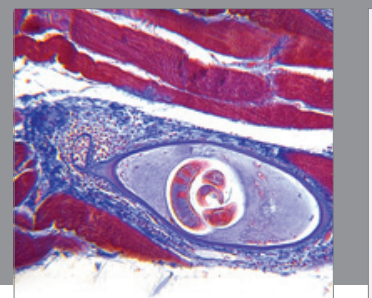

Gastroenterology

Research and Practice
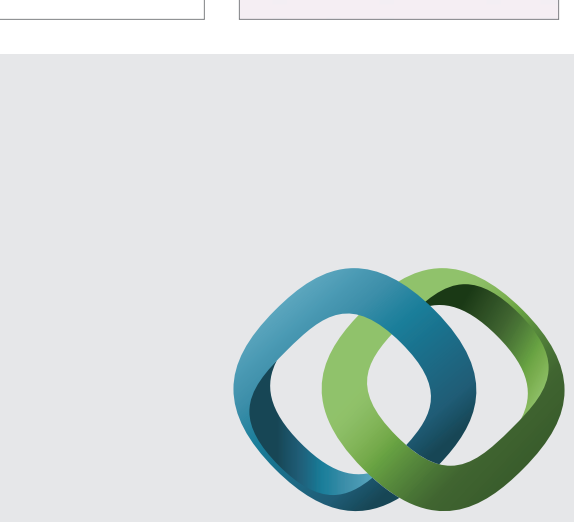

\section{Hindawi}

Submit your manuscripts at

http://www.hindawi.com
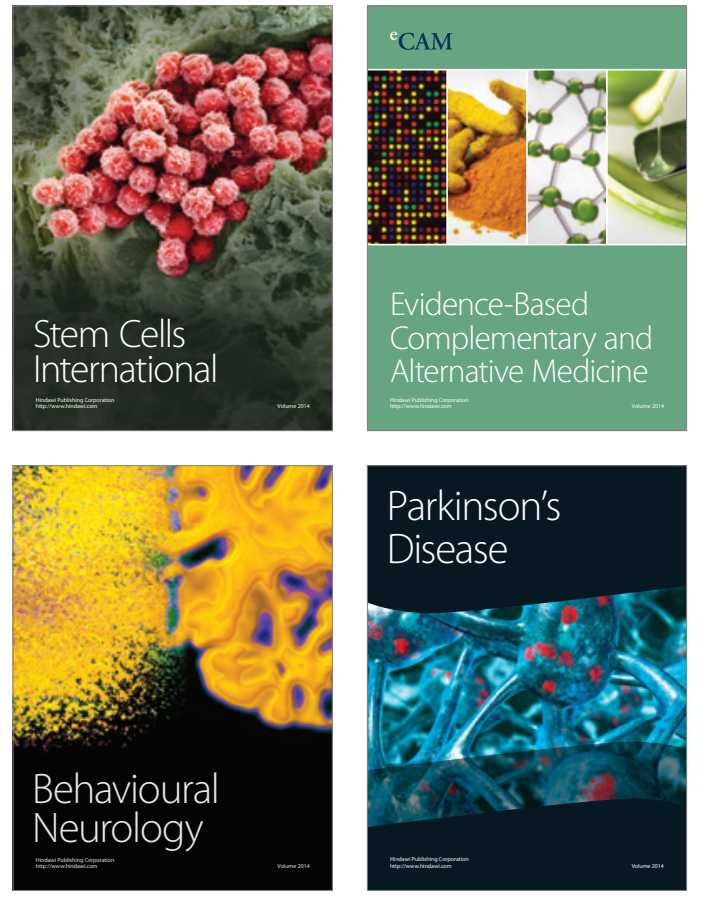
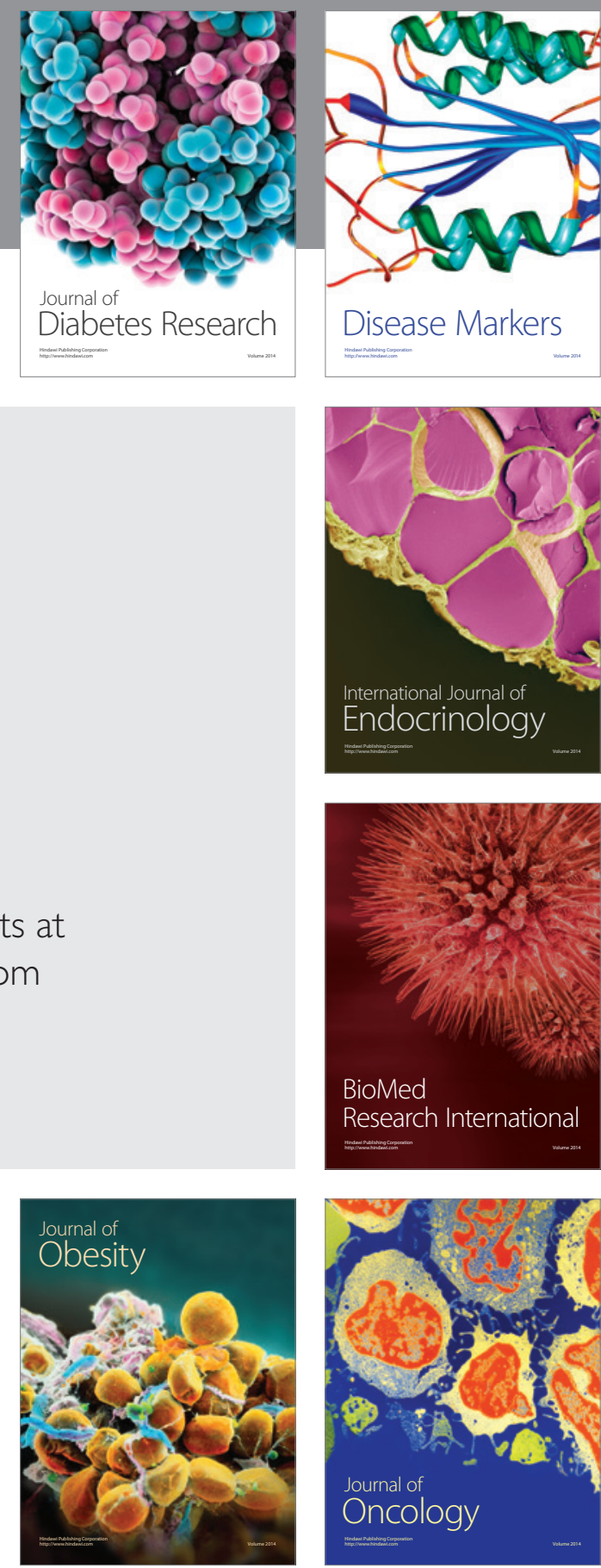

Disease Markers
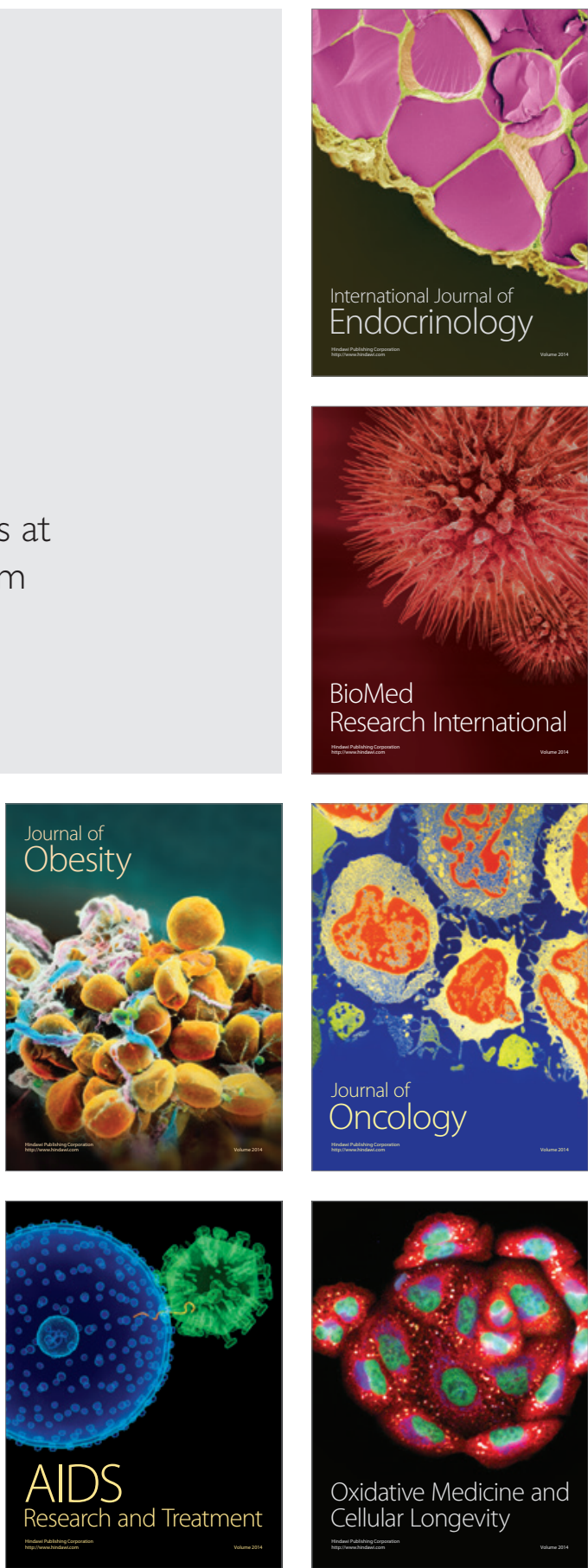